\title{
Endoscopic retrieval method using a small grip-seal plastic bag for large colorectal resection specimens after endoscopic submucosal dissection
}

Endoscopic submucosal dissection (ESD) has recently been developed for endoscopic treatment of colorectal polyps, enabling en bloc resection regardless of size and shape $[1,2]$. However, it is often difficult to retrieve a large resected colorectal specimen after ESD without damage to the specimen by the anal sphincter muscle. Here, we report an effective technique to retrieve a large colorectal resected specimen after ESD without damage. The polyp in this case was located in the rectum: a laterally spreading tumor, granular type, approximately $4 \mathrm{~cm}$ in diameter. En bloc resection of the polyp was successfully performed using the FlushKnife BT (Fujifilm, Tokyo, Japan). After the resec-
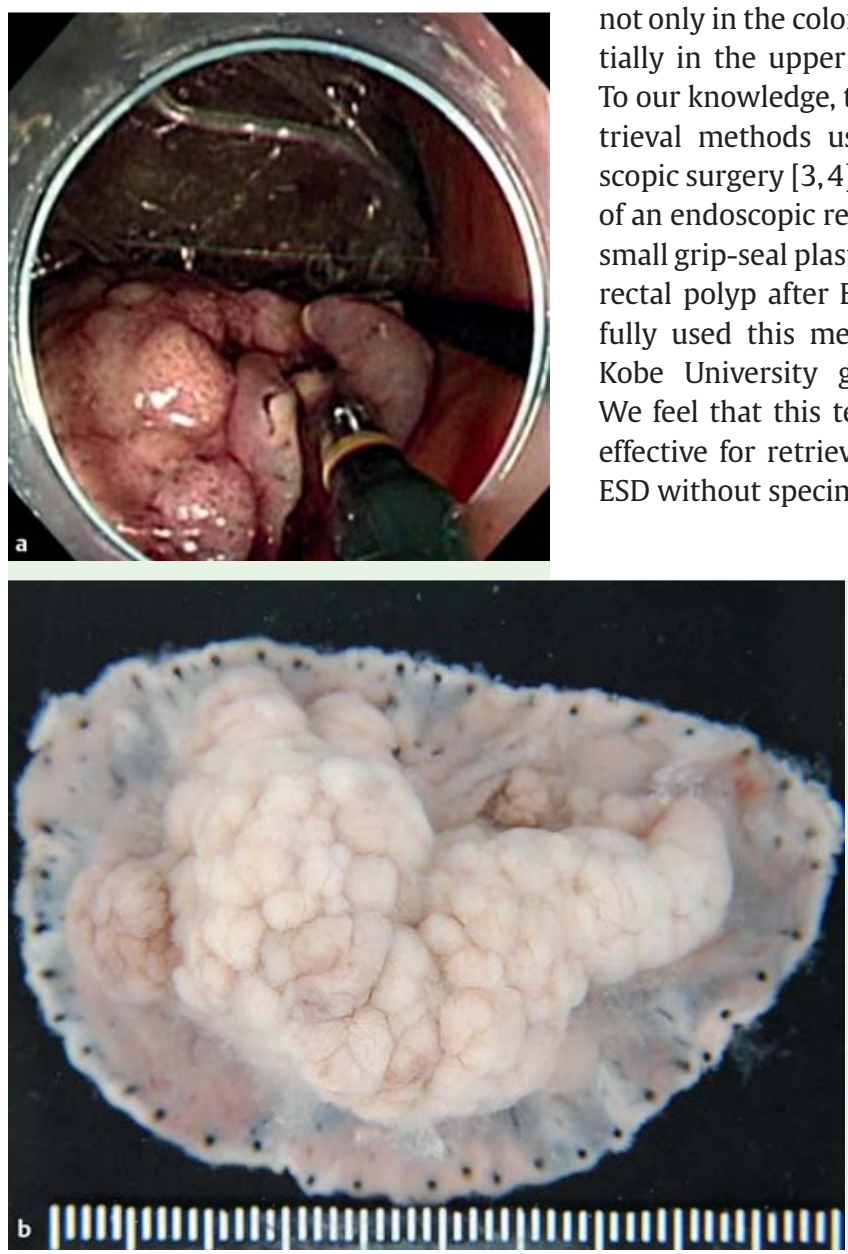

tion we reinserted the scope, which was covered with a small grip-seal plastic bag $(14 \times 8.5 \mathrm{~cm})$ ( Fig. $1 \mathrm{a})$. To expand the entrance of the bag, the top was grasped by an alligator forceps inserted alongside the scope ( Fig. 2a). The scope was withdrawn to free it from the plastic bag ( $\bullet$ Fig. 2 b). Next, another alligator forceps was inserted through the scope and the resected specimen was placed into the plastic bag using the second forceps ( $\bullet$ Fig. 2c). The plastic bag was then grasped by both sets of forceps and pulled out. The resected specimen was retrieved without damage by the anal sphincter muscle ( $\bullet$ Figs. $\mathbf{1}$ b, 2d).

Our technique is safe and easy, requires no special devices, and could be employed not only in the colorectum but also potentially in the upper gastrointestinal tract. To our knowledge, there are reports of retrieval methods using a bag in laparoscopic surgery $[3,4]$, but this is first report of an endoscopic retrieval method using a small grip-seal plastic bag for a large colorectal polyp after ESD. We have successfully used this method 10 times at the Kobe University gastroenterology unit. We feel that this technique is cheap and effective for retrieving large polyps after ESD without specimen damage.

Fig. 1 a Endoscopic view of retrieval method using a small gripseal plastic bag. Note forceps alongside the scope at $3 o^{\prime}$ clock in the image (equivalent to - Fig. 2c). b Specimen of the lesion resected by ESD and safely retrieved without damage using the plastic bag technique.

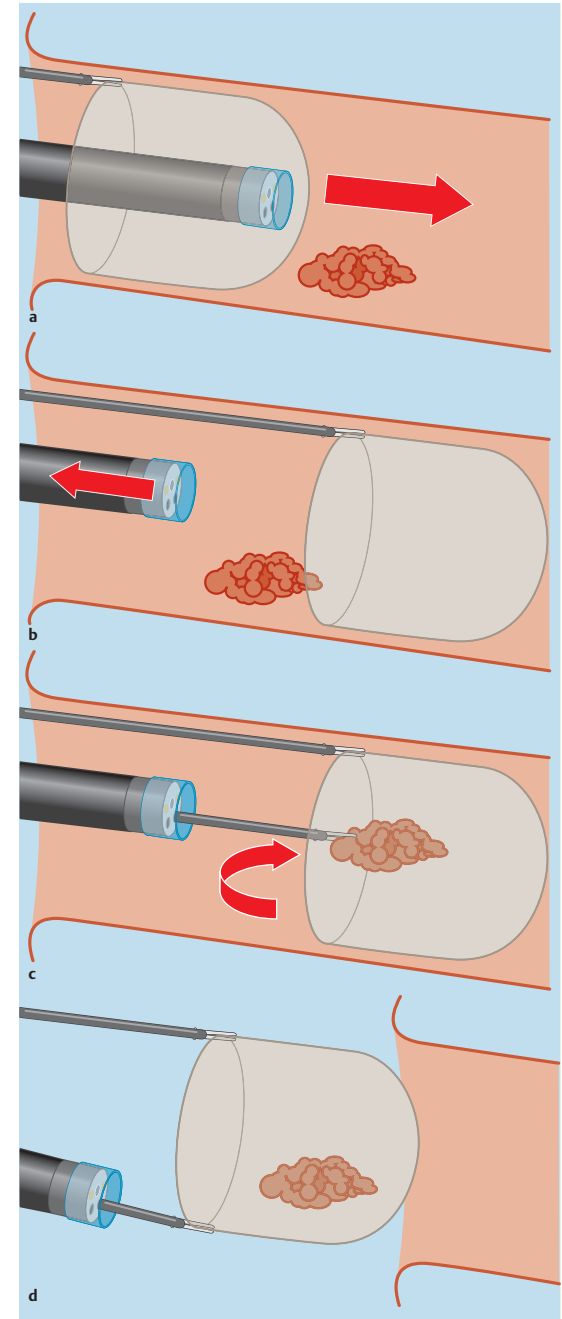

Fig. 2 Endoscopic retrieval method using a small plastic bag with zipper. a The scope is inserted covered with a small grip-seal plastic bag. The edge of the bag is grasped by an alligator forceps placed alongside the scope. b The scope is pulled out of the plastic bag. c The resected specimen is placed in the plastic bag using a second forceps introduced through the scope. $\mathbf{d}$ The plastic bag is pulled out using both sets of forceps together.

Competing interests: None

Endoscopy_UCTN_Code_TTT_1AQ_2AD 
S. Tanaka , T. Toyonaga ${ }^{1}$, J. East ${ }^{2}$,

D. Obata ${ }^{1}$, S. Fujiwara ${ }^{1}$, C. Wakahara ${ }^{1}$,

A. Masuda ${ }^{1}$, M. Man-i ${ }^{1}$, Y. Morita ${ }^{1}$,

T. Sanuki ${ }^{1}$, T. Fujita ${ }^{1}$, M. Yoshida ${ }^{1}$,

H. Kutsumi ${ }^{1}$, T. Azuma ${ }^{1}$

1 Division of Gastroenterology, Department of Internal Medicine, Graduate School of Medicine, Kobe University, Kobe, Hyogo, Japan

2 Department of Gastroenterology, John Radcliffe Hospital, Oxford, United Kingdom

\section{References}

1 Yamamoto $H$. Endoscopic submucosal dissection of early cancers and large flat adenomas. Clin Gastroenterol Hepatol 2005; 3: S74-S76

2 Yamamoto H, Kawata H, Sunada K et al. Successful en-bloc resection of large superficial tumors in the stomach and colon using sodium hyaluronate and small-caliber-tip transparent hood. Endoscopy 2003; 35: 690-694

3 Zacharoulis D, O'Boyle C, Royston CM et al. Splenic retrieval after laparoscopic splenectomy: a new bag. Laparoendosc Adv Surg Tech A 2006; 16: 128-132

4 Yao CC, Wong HH, Yang CC et al. Liberal use of a bag made from a surgical glove during laparoscopic surgery for specimens retrieval. Surg Laparosc Endosc Percutan Tech 2000; 10: $261-263$
Bibliography

DOI $10.1055 / \mathrm{s}-0029-1244168$

Endoscopy 2010; 42: E186 -E187

(c) Georg Thieme Verlag KG Stuttgart . New York . ISSN 0013-726X

\section{Corresponding author}

\section{T. Toyonaga, MD}

Division of Gastroenterology

Department of Internal Medicine

Graduate School of Medicine, Kobe University

7-5-1 Chu-o-ku, Kusunoki-Cho

Kobe, Hyogo 650-0017

Japan

toyonaga@med.kobe-u.ac.jp 